\title{
A pilot study on the usefulness of information and education campaign materials in enhancing the knowledge, attitude and practice on rabies in rural Sri Lanka
}

\author{
Gino C. Matibag ${ }^{1}$, Yoshihide Ohbayashi ${ }^{1}$, Koji Kanda ${ }^{1}$, Hiroko Yamashina ${ }^{1}$, \\ Bandula Kumara W. R. ${ }^{2}$, I. N. Gamini Perera ${ }^{3}$, D. D. Niranjala De Silva ${ }^{2}$, \\ G. S. Panduka De S. Gunawardena ${ }^{2}$, Ananda Jayasinghe ${ }^{4}$, \\ Rossana A. Ditangco ${ }^{1}$, Hiko Tamashiro ${ }^{1}$ \\ ${ }^{1}$ Department of Global Health and Epidemiology, Graduate School of Medicine, Hokkaido University, Kita-15 Nishi-7, Kita-Ku, \\ Sapporo 060-8638 Hokkaido, Japan \\ ${ }^{2}$ Faculty of Veterinary Medicine and Animal Science, University of Peradeniya, Peradeniya 20400 Sri Lanka \\ ${ }^{3}$ Department of Health Services-Central Province, Kandy, PO Box 163, Sangaraja, Mawatha, Kandy, Sri Lanka \\ ${ }^{4}$ Faculty of Medicine, University of Peradeniya, Peradeniya 20400 Sri Lanka
}

\begin{abstract}
Background: Rabies remains endemic in Sri Lanka despite a strong government patronized anti-rabies campaign. Personal, cultural or religious beliefs have been thought to influence health practices that could render rabies prevalent in the country.

Methodology: The knowledge, attitudes, and beliefs of 580 household heads/members from Nuwara Eliya District, Sri Lanka, regarding rabies were explored through a structured questionnaire. An improvement/deterioration in their knowledge and practices after the use of information and education campaign (IEC) materials was assessed through a repeat exploration at an interval of four weeks.

Results: Respondents showed inclination toward animal birth control $(60 \%)$ rather than elimination methods (24\%). There was disparity between pet owners' enthusiasm to take pets for rabies inoculation (57\%) and their ability to show dog vaccination cards (40\%). Almost twice more pet owners than non-pet owners believed that it is their responsibility to control the population of roaming pet dogs $(\mathrm{aOR}=1.78$; 95\% CI: 1.14 to 2.76). The rabies leaflets were very effective in informing the people on how to deal with rabid animals, the earliest schedule for anti-rabies vaccine (ARV), and repeat vaccination.

Conclusions: Awareness and proper attitude toward rabies management and canine population control are adequate among the rural Sinhalese and Buddhist populations of Sri Lanka; however, their current health practices should be improved. The rabies KAP could be further enhanced through the use of IEC materials.
\end{abstract}

Key Words: Rabies; knowledge; attitude; health practice; Sri Lanka

J Infect Developing Countries 2009; 3(1):55-64.

Received 22 July 2008 - Accepted 22 September 2008

Copyright $\odot 2008$ Matibag et al. This is an open access article distributed under the Creative Commons Attribution License, which permits unrestricted use, distribution, and reproduction in any medium, provided the original work is properly cited.

\section{Introduction}

Of the estimated 55,000 annual deaths due to human rabies in the world, more than 33,000 fatalities are likely to take place in the South-East Asia Region (SEAR). Rabies is endemic in seven countries of the SEAR (Bangladesh, India, Indonesia, Myanmar, Nepal, Sri Lanka, and Thailand) with the exception of Bhutan, DPR Korea, Maldives, and Timor-Leste. The estimated annual cost of human and animal anti-rabies biologics in the region is US\$57 million [1-3]. Although Sri Lanka has been implementing rabies control programs for nearly three decades, rabies remains a public health threat in the country. Between 1973 and 2008, although there were fluctuations, a decreasing trend in incidence was observed. In 1973, the country recorded its highest number of human rabies deaths of 377 (20 per million population) and the lowest of 55 (3 per million population) in 2005 [4-6]. According to the World Health Organization (WHO), between 1987 and 2007, with the total number of human fatalities reaching 2,042 , the country ranks number three in the region and seven in the world in disease fatalities (India 24,4478; Bangladesh 22,900; China 13,995; Philippines 5,658; Viet Nam 5,183; Pakistan 2,843; Myanmar 1,683; Thailand 1,377; Indonesia 1,208) [6]. From 2003 to 
2007, Sri Lanka reported 359 (19 per million population) human rabies deaths (range: 55-97) [6-9].

Persistence, and to some extent expansion, of the overall rabies situation in the countries of the region indicate inadequacy of control activities. The various constraints that are responsible for the situation include:

a) lack of a national policy and a comprehensively coordinated national rabies control program

b) inadequacies in partnership between stakeholders, infrastructure and capacity, quantities of safe and potent immunizing agents, and dog population management programmes

c) non-implementation of technically sound strategies

d) weak epidemiological surveillance

e) inadequate research and development and absence of health education.

In the SEAR, information and education campaign (IEC) activities are few and far between. Efforts to educate the public about the epidemiological features of rabies and simple "Dos and Don'ts" that can protect them as well as help in bringing about a reduction in the incidence of rabies are nil [1].

A study on rabies knowledge, attitude and practice (KAP) in Kandy District, Central Province, showed that there was high level of awareness and receptiveness to rabies control measures among the people [10]. The practice attributes relevant to rabies control in urban and rural areas were dismal. The practices that need to be improved include: reporting of dog bites; knowledge and enthusiasm to take suspected animals to a diagnostic laboratory for disease confirmation; preference for animal birth control $(\mathrm{ABC})$ as against euthanasia; seeking medical treatment after a dog bite; pet restriction and vaccination. Pet owners were more supportive of rabies control activities than non-pet owners. It was also noted that the willingness and awareness of the people did not guarantee that they would cooperate in government rabies control programs [10].

It is possible that religious beliefs have played a role in the persistence of rabies in the country. The major religions, Buddhism and Hinduism, do not favor slaughter of animals and hence the "capture and kill" policy is widely deemed unacceptable [11-15]. Considering this, the government encourages and provides mass canine vaccination and sterilization to control rabies and dog population growth $[10,16]$. Like Thailand, destruction of dogs and cats is rarely practiced in Sri Lanka due to firmly rooted Buddhist ethics [17-19]. An earlier survey showed a low rate of submission of animal specimens for laboratory confirmation of rabies (2/357), which is inconsistent with the respondents' will to destroy rabies-suspect pets $(71.1 \%)$ and strays $(85.5 \%)[10,20]$. In neighboring India, a predominantly Hindu nation, $74.5 \%$ of animals responsible for the bites were killed in order to avert potential harm to humans [21].

From 2003 to 2006, although there was improvement in canine rabies vaccination in Sri Lanka (30\%, 32\%, 38\% and 42\%), the overall coverage still remains low [6]. In Kandy District, 58\% of households were pet owners and only $48 \%$ of pet dogs were vaccinated. It is a common practice among dog owners $(33 \%)$ to allow pets to roam around unsupervised and $8.5 \%$ of these animals have no cages and stay within the house of their owners, which could increase the possibility of dog bites [10].

In order to control the disease, knowledge about rabies, proper and adequate pet care practices, and responsible dog ownership should be emphasized to the people, especially those in rural areas [10]. Health educational drives through the use of IEC materials may be a cost-effective method to disseminate correct information to the priority population.

Thus, we conducted a pilot study in three selected rural communities in Sri Lanka. This study will serve as a basis to strategize for further anti-rabies interventions in the future. The objectives of this study are to compare the KAP of people in Nuwara Eliya District, and to evaluate the effect of IEC materials (rabies leaflets) with regard to knowledge about rabies, pet care, and responsible ownership of dogs.

\section{Materials and Methods}

\section{Study design}

This biphasic exploratory study was conducted from 31 January to 15 February 2008 (pre-intervention) and from 7 to 19 March 2008 (post-intervention).

\section{Study locations, sampling and sample population}

Armed conflicts, bombing episodes, and security concerns in different parts of Sri Lanka have been major constraints to random selection of study areas at the time of survey [22-26]. Thus, the survey was conducted in a fairly safe location in Hanguranketa Division, Nuwara Eliya (NE) District, Central Province (7010'39.01'N, 80046'43.05'E, elevation: 1,990 meters). Within this mountainous rural division, three villages were selected, namely, Rikillagaskada (2007 population: 1,490 residents; 441 households), Kottala (962 residents; 231 households), and Ambaliyedda (834 
residents; 195 households) (Figure 1) [27]. Prioritizing the remote areas, we selected these three villages due to a low canine rabies vaccination coverage and, hence possibly an inadequate rabies information campaign. Household selection started from the health center of each village and went outwardly. Whereas qualified household heads/members in Rikillagaskada were chosen from every other house on sight, we enrolled all willing and capable respondents in Kottala and Ambaliyedda. When no eligible respondents were available, the house was revisited the following day. For this study, a rural area would be a rural or an estate sector (plantation areas having more than 20 acres/8 hectares and more than 10 residential laborers with

Figure 1. Map of Hanguranketa Division showing the locations of the three study areas (A-Rikillagaskada, BKottala, $C$-Ambaliyedda). Insert shows the three districts that compose the Central Province of Sri Lanka (1-Matale, 2Kandy, 3-Nuwara Eliya).

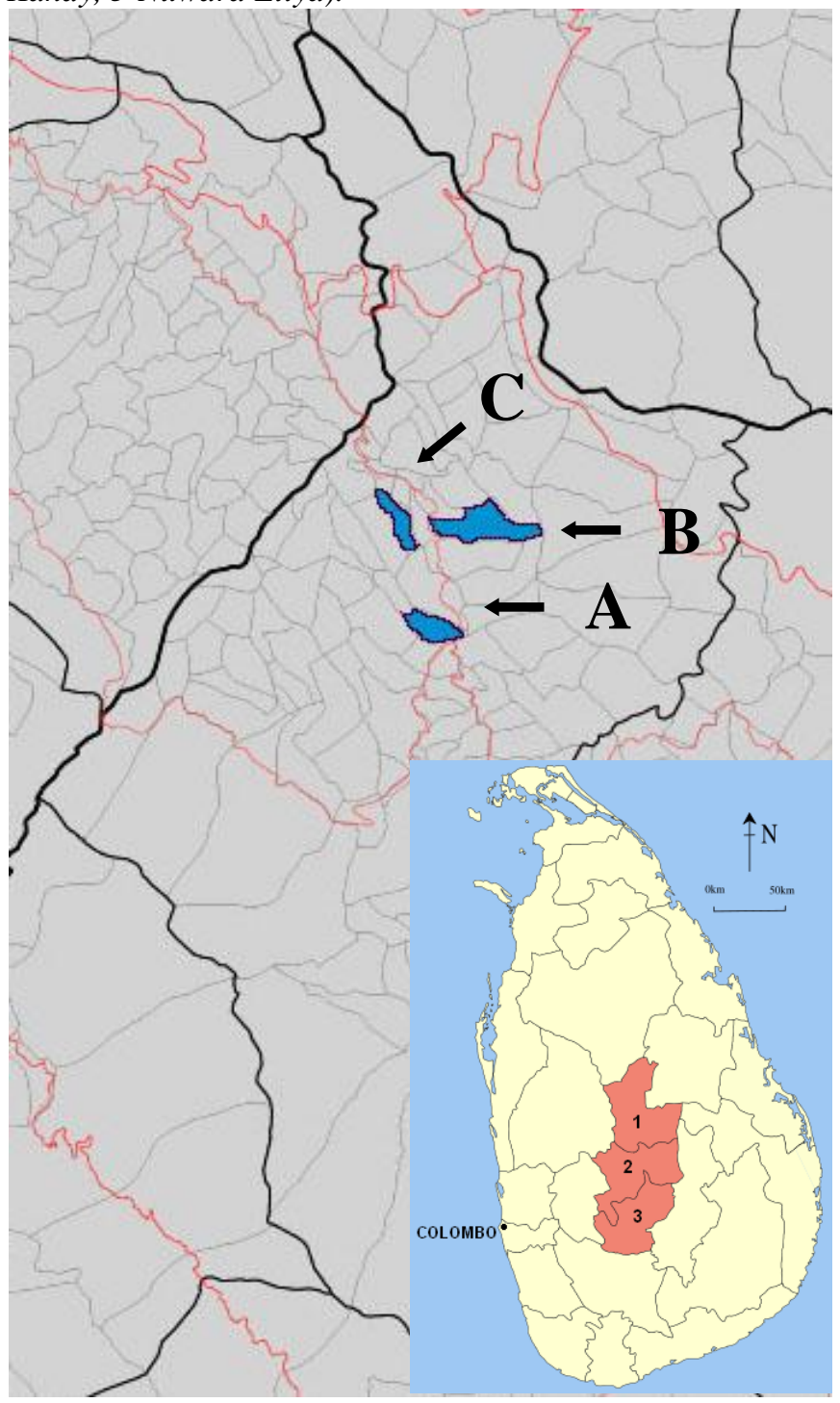

a single administration body) [28].

The population distribution is similar between the NE District and Sri Lanka with regard to age, gender, and educational attainment. However, in contrast to national data (rural: 85\%; Tamil race: 9\%; Hinduism: $8 \%)$, the rural sector (94\%), Tamil (57\%), and Hinduism $(51 \%)$ were over-represented in the NE District [28,29]. Face-to-face interviews were conducted for all available household heads/members aged 15 and above who consented and were available during weekday interviews (10:00-16:00) for baseline and follow-up periods. Only one respondent was interviewed for every household.

For the pre-intervention study, a total of 676 houses were visited. Of these, 602 household members agreed to participate. During the post-intervention study, 594 respondents were available for interview. There were 14 questionnaires that did not match for age or sex of the respondents for the pre- and post-intervention interviews, hence, were disregarded. A total of 580 respondents were included in the final analysis.

\section{Survey method and questionnaire}

A standard structured questionnaire was developed to assess the respondents' KAP before and after the use of IEC materials. The questionnaire included items regarding respondents' profile, levels of KAP with respect to rabies and dog population management and control, pet care practices, and responsible dog ownership. The English questionnaire was translated to Sinhalese with back-translation to ensure accuracy. Pretesting was performed prior to the actual survey.

After the baseline interview, the study participants were given a copy of the rabies IEC leaflet and were encouraged to read the material. They were also informed that a follow-up interview would be held four weeks later to determine any change in rabies KAP. All study participants were included during the follow-up interview. No new participants were recruited. Those who were not available, despite repeated visits during the post-intervention period, were excluded from the study.

\section{IEC materials}

Rabies leaflets were developed in English and translated to Sinhalese. The following information was included: the nature of human rabies, signs and symptoms of human and canine rabies, modes of transmission, what to do after an animal bite, proper and adequate pet care practices, and responsible dog ownership. The information was drafted from various 
sources such as the WHO, pet care websites, and from veterinary faculty members of the University of Peradeniya [30-35]. Colorful illustrations were included to attract and encourage the participants to read the material. All respondents were provided one copy each.

\section{Ethical clearance}

Approval for the study was obtained from the Ethics Committee of the University of Peradeniya, Sri Lanka. A clearance for conducting the survey was also acquired from the Department of Health Services of Central Province.

\section{Data analysis}

The priority population was grouped according to pet ownership status and highest educational attainment. The Chi-square test or Fisher's exact test was used, as appropriate, to evaluate the statistical significance of the differences in responses of participants. To compare the change in KAP, the McNemar change test was used. A $P$ value of $<0.05$ was considered to be statistically significant. To control the effects of gender and educational level on the responses, logistic regression analysis was applied. Data analysis was done using SPSS version 14.0.

\section{Results}

\section{Demographic characteristics of the study population}

The median age of the respondents was 40 years (mean: $42.02 \pm 1.27$ ). Male subjects comprised $35.5 \%$ of the cohort (median: 48 years; mean: 46.32 \pm 2.15 ). Female subjects constituted $64.5 \%$ of the population (median: 36 years; mean: 39.66 \pm 1.53 ). There were no significant differences in age and gender distribution, educational attainment, religion, ethnicity, and use of tri-media resources between pet- and non-pet owners (Table 1).

The majority of respondents had heard of rabies $(94.5 \%)$. Most of the information came from various sources such as tri-media (radio, newspaper, television) (44.3\%); school, neighbors and friends (28.5\%); and government campaigns (26.5\%). Most of the respondents $(89.7 \%)$ read the leaflet provided to them. Approximately $89.0 \%$ agreed that the IEC materials were useful (Table 1).

\section{Attitude toward control of rabies and dog population growth}

Both pet- and non-pet owners agreed that 1) stray dogs are annoying $(P=0.428) ; 2) \mathrm{ABC}$ methods are the
Table 1. Demographic characteristics of respondents in selected areas of Nuwara Eliya, Sri Lanka.

\begin{tabular}{|c|c|c|c|c|c|c|c|}
\hline \multirow{2}{*}{ 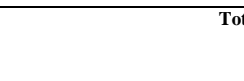 } & \multicolumn{2}{|c|}{ Total no. of respondents } & \multicolumn{2}{|c|}{ Pet owner } & \multicolumn{2}{|c|}{ Non-pet owner } & \multirow{2}{*}{$\begin{array}{r}p \\
\text { value }\end{array}$} \\
\hline & \multicolumn{2}{|l|}{$\mathrm{n}=\mathbf{5 8 0}$} & \multicolumn{2}{|l|}{$\mathrm{n}=\mathbf{2 8 4}$} & \multicolumn{2}{|l|}{$\mathrm{n}=296$} & \\
\hline Gender & & & & & & & \\
\hline & 206 & $35.5 \%$ & 110 & $38.7 \%$ & 96 & $32.4 \%$ & 0.119 \\
\hline Female & 374 & $64.5 \%$ & 174 & $61.3 \%$ & 200 & $67.6 \%$ & \\
\hline \multicolumn{8}{|l|}{ Age (years) ${ }^{*}$} \\
\hline $15-19$ & 29 & $5.1 \%$ & 18 & $6.6 \%$ & 11 & $3.8 \%$ & $0.592^{\text {II }}$ \\
\hline $20-29$ & 96 & $17.0 \%$ & 41 & $15.0 \%$ & 55 & $19.0 \%$ & \\
\hline $30-39$ & 148 & $26.2 \%$ & 62 & $22.6 \%$ & 86 & $29.7 \%$ & \\
\hline $40-49$ & 107 & $19.0 \%$ & 57 & $20.8 \%$ & 50 & $17.2 \%$ & \\
\hline $50-59$ & 96 & $17.0 \%$ & 60 & $21.9 \%$ & 36 & $12.4 \%$ & \\
\hline$\geq 60$ & 88 & $15.6 \%$ & 36 & $13.1 \%$ & 52 & $17.9 \%$ & \\
\hline \multicolumn{8}{|l|}{ Educational level } \\
\hline Primary $^{\dagger}$ & 216 & $37.2 \%$ & 101 & $35.6 \%$ & 115 & $38.9 \%$ & 0.609 \\
\hline Secondary and above $e^{\ddagger}$ & 350 & $60.3 \%$ & 177 & $62.3 \%$ & 173 & $58.4 \%$ & \\
\hline Not stated & 14 & $2.4 \%$ & 6 & $2.1 \%$ & 8 & $2.7 \%$ & \\
\hline \multicolumn{8}{|l|}{ Religion } \\
\hline Buddhism & 569 & $98.1 \%$ & 280 & $98.6 \%$ & 289 & $97.6 \%$ & 0.554 \\
\hline Hinduism/Islam/Christianity & 7 & $1.2 \%$ & 2 & $0.7 \%$ & 5 & $1.7 \%$ & \\
\hline Not stated & 4 & $0.7 \%$ & 2 & $0.7 \%$ & 2 & $0.7 \%$ & \\
\hline \multicolumn{8}{|l|}{ Ethnicity } \\
\hline Sinhalese & 575 & $99.1 \%$ & 283 & $99.6 \%$ & 292 & $98.6 \%$ & 0.373 \\
\hline Tamil/Moor & 5 & $0.9 \%$ & 1 & $0.4 \%$ & 4 & $1.4 \%$ & \\
\hline \multicolumn{8}{|l|}{ No. of households surveyed } \\
\hline Rikillagaskada & 206 & $35.5 \%$ & 95 & $33.5 \%$ & 111 & $37.5 \%$ & 0.007 \\
\hline Kottala & 199 & $34.3 \%$ & 115 & $40.5 \%$ & 84 & $28.4 \%$ & \\
\hline Ambaliyedda & 175 & $30.2 \%$ & 74 & $26.1 \%$ & 101 & $34.1 \%$ & \\
\hline \multicolumn{8}{|l|}{ No. of household members } \\
\hline Male & 1227 & $49.9 \%$ & 627 & $49.8 \%$ & 600 & $49.9 \%$ & $0.028^{\mathrm{II}}$ \\
\hline Female & 1234 & $50.1 \%$ & 633 & $50.2 \%$ & 601 & $50.1 \%$ & $0.020^{\mathrm{II}}$ \\
\hline Average household size & \multicolumn{2}{|c|}{$4.24 \pm 0.11$} & \multicolumn{2}{|c|}{$4.44 \pm 0.17$} & \multicolumn{2}{|c|}{$4.06 \pm 0.15$} & $0.001^{\mathrm{II}}$ \\
\hline Average monthly & \multicolumn{2}{|c|}{$9775.82 \pm 945.65$} & \multicolumn{2}{|c|}{$9518.72 \pm 1123.52$} & \multicolumn{2}{|c|}{$10067.09 \pm 1577.21$} & $0.570^{\text {II }}$ \\
\hline $\begin{array}{l}\text { household } \\
\text { (Rupees) }\end{array}$ & & & & & & & \\
\hline \multicolumn{8}{|l|}{ Have heard about rabies } \\
\hline Yes & 548 & $94.5 \%$ & 273 & $96.1 \%$ & 275 & $92.9 \%$ & 0.208 \\
\hline No & 25 & $4.3 \%$ & 8 & $2.8 \%$ & 17 & $5.7 \%$ & \\
\hline No answer & 7 & $1.2 \%$ & 3 & $1.1 \%$ & 4 & $1.4 \%$ & \\
\hline Sources of information ${ }^{8}$ & & & & & & & \\
\hline Tri-mediall & 491 & $44.3 \%$ & 239 & $43.5 \%$ & 252 & $45.2 \%$ & 0.457 \\
\hline School/Friends/Neighbors & 316 & $28.5 \%$ & 150 & $27.3 \%$ & 166 & $29.7 \%$ & \\
\hline $\begin{array}{l}\text { Government rabies } \\
\text { vaccination campaigns }\end{array}$ & 294 & $26.5 \%$ & 157 & $28.5 \%$ & 137 & $24.6 \%$ & \\
\hline $\begin{array}{l}\text { Did not receive information } \\
\text { Study participants read the }\end{array}$ & aflet & $0.6 \%$ & 4 & $0.7 \%$ & 3 & $0.5 \%$ & \\
\hline Yes & 520 & $89.7 \%$ & 260 & $91.5 \%$ & 260 & $87.8 \%$ & 0.164 \\
\hline No & 59 & $10.2 \%$ & 23 & $8.1 \%$ & 36 & $12.2 \%$ & \\
\hline No answer & 1 & $0.2 \%$ & 1 & $0.4 \%$ & 0 & $0.0 \%$ & \\
\hline Leaflet was useful & & & & & & & \\
\hline Yes & 516 & $89.0 \%$ & 258 & $90.8 \%$ & 258 & $87.2 \%$ & 0.263 \\
\hline No & 1 & $0.2 \%$ & 0 & $0.0 \%$ & 1 & $0.3 \%$ & \\
\hline Undecided & 63 & $10.9 \%$ & 26 & $9.2 \%$ & 37 & $12.5 \%$ & \\
\hline
\end{tabular}

*Missing data were excluded in the analysis. †Includes no schooling, Kindergarten up to Grade 10. \$Has passed the General Certificate of Education, Ordinary Level Examination including college level and above. §Some information sources were counted more than once. $\|$ Television, radio, and newspaper IIOne-way ANOVA.

best measures to control stray dog population $(P=$ $0.267)$; 3 ) it is the responsibility of the people and nongovernmental organizations (NGOs) to control the population of poorly supervised pet $\operatorname{dogs}(P=0.737)$ (Table 2).

Controlling for respondents' age and educational level, pet owners were more likely than non-pet owners to think that 1) it is the people and NGOs who are responsible in controlling stray dog population 
Table 2. Attitude toward control of rabies and dog population among respondents in selected areas of Nuwara Eliya, Sri Lanka.

\begin{tabular}{|c|c|c|c|c|c|c|c|}
\hline & \multicolumn{2}{|c|}{ Total no. of respondents } & \multicolumn{2}{|c|}{ Pet owner } & \multicolumn{2}{|c|}{ Non-pet owner } & \multirow{2}{*}{$\begin{aligned} p \\
\text { value }\end{aligned}$} \\
\hline & $\mathrm{n}=\mathbf{5 8 0}$ & $\%$ & $\mathrm{n}=\mathbf{2 8 4}$ & $\%$ & $\mathrm{n}=296$ & $\%$ & \\
\hline \multicolumn{8}{|c|}{ Are you annoyed with stray dogs? } \\
\hline Yes & 463 & 79.8 & 232 & 81.7 & 231 & 78.0 & 0.428 \\
\hline No & 30 & 5.2 & 15 & 5.3 & 15 & 5.1 & \\
\hline Undecided & 87 & 15.0 & 37 & 13.0 & 50 & 16.9 & \\
\hline \multicolumn{8}{|c|}{$\begin{array}{l}\text { Which of the following procedures do you think is the best thing to do to control stray dog } \\
\text { population? }\end{array}$} \\
\hline Animal birth control & 350 & 60.3 & 179 & 63.0 & 171 & 57.8 & 0.267 \\
\hline Other" & 141 & 24.3 & 68 & 23.9 & 73 & 24.7 & \\
\hline Undecided & 89 & 15.3 & 37 & 13.0 & 52 & 17.6 & \\
\hline \multicolumn{8}{|c|}{$\begin{array}{l}\text { Who or which institution/agency do you think should be responsible in controlling the stray dog } \\
\text { population? }\end{array}$} \\
\hline $\begin{array}{l}\text { People in the } \\
\text { community/NGOs }\end{array}$ & 383 & 66.0 & 205 & 72.2 & 178 & 60.1 & 0.008 \\
\hline Government & 111 & 19.1 & 43 & 15.1 & 68 & 23.0 & \\
\hline Undecided & 86 & 14.8 & 36 & 12.7 & 50 & 16.9 & \\
\hline \multicolumn{8}{|c|}{$\begin{array}{l}\text { Which of the following procedures do you think would be best to control the population of } \\
\text { poorly supervised pet dogs? }\end{array}$} \\
\hline Animal birth control & 384 & 66.2 & 204 & 71.8 & 180 & 60.8 & 0.016 \\
\hline Other ${ }^{*}$ & 111 & 19.1 & 43 & 15.1 & 68 & 23.0 & \\
\hline Undecided & 85 & 14.7 & 37 & 13.0 & 48 & 16.2 & \\
\hline \multicolumn{8}{|c|}{$\begin{array}{l}\text { Who or which institution/agency do you think should be responsible in controlling the poorly } \\
\text { supervised pet dog population? }\end{array}$} \\
\hline $\begin{array}{l}\text { People in the } \\
\text { community/NGOs }\end{array}$ & 405 & 69.8 & 202 & 71.1 & 203 & 68.6 & 0.737 \\
\hline Government & 74 & 12.8 & 36 & 12.7 & 38 & 12.8 & \\
\hline Undecided & 101 & 17.4 & 46 & 16.2 & 55 & 18.6 & \\
\hline \multicolumn{8}{|c|}{$\begin{array}{l}\text { In your community, if there is a regulation banning stray dogs, are you willing to report to } \\
\text { authorities if you see one? }\end{array}$} \\
\hline Yes & 469 & 80.9 & 241 & 84.9 & 228 & 77.0 & 0.050 \\
\hline No & 18 & 3.1 & 6 & 2.1 & 12 & 4.1 & \\
\hline Undecided & 93 & 16.0 & 37 & 13.0 & 56 & 18.9 & \\
\hline \multicolumn{8}{|c|}{$\begin{array}{l}\text { In your community, if there is a regulation banning owned but poorly supervised dogs, are you } \\
\text { willing to report to authorities if you see one? }\end{array}$} \\
\hline Yes & 418 & 72.1 & 218 & 76.8 & 200 & 67.6 & 0.041 \\
\hline No & 63 & 10.9 & 24 & 8.5 & 39 & 13.2 & \\
\hline Undecided & 99 & 17.1 & 42 & 14.8 & 57 & 19.3 & \\
\hline
\end{tabular}

"Dog elimination; pound/restriction methods. "Non-governmental organizations.

(adjusted OR $=1.778 ; 95 \% \mathrm{CI}: 1.145-2.761 ; P=$ $0.010)$; 2) the best way to control the population of poorly supervised pet dogs is through $\mathrm{ABC}$ methods (adjusted OR $=1.837 ; 95 \%$ CI: $1.185-2.848 ; P=$ $0.007)$; 3) poorly supervised pets should be reported to authorities (adjusted OR $=1.771 ; 95 \%$ CI: 1.029-3.050; $P=0.039)$.

\section{Practice of responsible dog ownership}

Although most dog owners (57.4\%) were willing to take their pets to free rabies vaccination campaigns, only $40.5 \%$ of them were able to show certificates. Approximately $65.1 \%$ of dog owners preferred hormonal contraceptive methods while $58.1 \%$ preferred castration and/or ovariohysterectomy for their pets.
Among the reasons for not favoring non-surgical and surgical methods of dog population control included personal beliefs and religion $(10.2 \%, 16.5)$ and ownerspecific reasons such as having no time to take pets and ignorance of vaccination schedule $(6.0 \%, 10.6 \%)$. Most dog owners kept their old and disabled pets $(67.3 \%)$ and gave to other people their new puppies (47.5\%). Approximately half (48.9\%) of pet owners claimed that their dogs never go to other households or in the street for food (Table 3).

\section{Effect of educational attainment}

In general, there were no differences in the participants' attitudes, beliefs, and health practices related to rabies and pet care based on educational level except that there were more respondents with a higher level of education (secondary level and above) who read the IEC materials $(94.9 \%$ vs. $87.7 \%, P=0.039)$ and found them useful (93.6\% vs. 87.2\%, $P=0.015$ ) (Data not shown).

\section{Change in KAP toward rabies, pet care and responsible} ownership of dogs

After reading the IEC material, there was a significant improvement in KAP for both pet- and nonpet owners regarding the following: 1) the most common mode of rabies transmission is through bites of infected animals (pet owner: 4.9\%. $P=0.045$; non-pet owner: $7.7 \%, P=0.015) ; 2$ ) the most common source of rabies in Sri Lanka is the dog (pet owner: $4.9 \%$, $P=0.039$; non-pet owner: $6.8 \%, P=0.001)$; 3 ) rabid animals should be captured and sent to laboratory (pet owner: $67.9 \%, P=0.000$; non-pet owner: $62.1 \%$, $P=0.000)$; 4) pet dogs should be registered to local authorities by three months of age (pet owner: $7.1 \%$, $P=0.012$ : non-pet owner: $10.8 \%, P=0.002) ; 5)$ risk perception for rabies (pet owner: $6.3 \%, P=0.038$; nonpet owner: $5.1 \%, P=0.002)$; 6) dogs should receive rabies vaccine by six weeks of age (pet owner: $36.2 \%$, $P=0.000$; non-pet owner: $45.3 \%, P=0.000$ ). Among pet owners, there were improvements in showing dog registration certificates $(9.1 \%, P=0.454)$ and providing cages for their pets $(7.1 \%, P=0.003)$. However, there was a decrease in percentage among those who never allowed their pets to roam unsupervised $(-10.9 \%, P=$ 0.006) (Table 4).

Improvement in KAP aspects for pet- and non-pet owners differed for the following points: 1) misconceptions on the mode of transmission of rabies (urine from an infected animal, eating street foods, and 
Table 3. Practice of responsible dog ownership in Nuwara Eliya, Sri Lanka according to educational attainment.

\begin{tabular}{|c|c|c|c|c|c|c|c|}
\hline & \multicolumn{2}{|c|}{ Total no. of pet owners } & \multicolumn{2}{|c|}{ Primary ${ }^{*}$} & \multicolumn{2}{|c|}{ Secondary $^{\dagger}$} & \multirow{2}{*}{$\begin{array}{r}p \\
\text { value }\end{array}$} \\
\hline & $\mathrm{n}=284$ & $\%$ & $\mathrm{n}=206$ & $\%$ & $\mathrm{n}=78$ & $\%$ & \\
\hline \multicolumn{8}{|c|}{ Do you want your pet to undergo free surgical castration or ovariohysterectomy for birth control? } \\
\hline Yes to both procedures & 165 & 58.1 & 115 & 55.8 & 50 & 64.1 & 0.319 \\
\hline Yes to surgical castration only & 16 & 5.6 & 15 & 7.3 & 1 & 1.3 & \\
\hline Yes to ovariohysterectomy only & 15 & 5.3 & 12 & 5.8 & 3 & 3.8 & \\
\hline No to both procedures & 44 & 15.5 & 32 & 15.5 & 12 & 15.4 & \\
\hline Undecided & 44 & 15.5 & 32 & 15.5 & 12 & 15.4 & \\
\hline \multicolumn{8}{|c|}{ Reasons for not being in favor of surgical castration and/or ovariohysterectomy for pet dogs } \\
\hline Against beliefs and/or religion ${ }^{\ddagger}$ & 47 & 16.5 & 30 & 14.6 & 17 & 21.8 & 0.340 \\
\hline Other ${ }^{8}$ & 30 & 10.6 & 22 & 10.7 & 8 & 10.3 & \\
\hline Uncertain & 207 & 72.9 & 154 & 74.8 & 53 & 67.9 & \\
\hline \multicolumn{8}{|c|}{ Do you want your pet to undergo free contraceptive injection for birth control? } \\
\hline Yes & 185 & 65.1 & 131 & 63.6 & 54 & 69.2 & 0.426 \\
\hline No & 50 & 17.6 & 40 & 19.4 & 10 & 12.8 & \\
\hline Undecided & 49 & 17.3 & 35 & 17.0 & 14 & 17.9 & \\
\hline \multicolumn{8}{|c|}{ Reasons for not being in favor of contraceptive injection for pet dogs? } \\
\hline Against beliefs and/or religion ${ }^{\ddagger}$ & 29 & 10.2 & 24 & 11.7 & 5 & 6.4 & 0.427 \\
\hline Other ${ }^{8}$ & 17 & 6.0 & 12 & 5.8 & 5 & 6.4 & \\
\hline Uncertain & 238 & 83.8 & 170 & 82.5 & 68 & 87.2 & \\
\hline \multicolumn{8}{|c|}{ When you had puppies, what did you do to them? } \\
\hline Gave to other people/Abandoned & 135 & 47.5 & 95 & 46.1 & 40 & 51.3 & 0.735 \\
\hline I kept the puppies & 46 & 16.2 & 34 & 16.5 & 12 & 15.4 & \\
\hline No answer & 103 & 36.3 & 77 & 37.4 & 26 & 33.3 & \\
\hline \multicolumn{8}{|c|}{ What did you do to your old or disabled pet dogs? } \\
\hline Gave to other people/Abandoned & 33 & 11.6 & 20 & 9.7 & 13 & 16.7 & 0.185 \\
\hline I kept my old or disabled dogs & 191 & 67.3 & 139 & 67.5 & 52 & 66.7 & \\
\hline No answer & 60 & 21.1 & 47 & 22.8 & 13 & 16.7 & \\
\hline \multicolumn{8}{|c|}{ Willing to take dogs for rabies vaccination } \\
\hline Yes & 163 & 57.4 & 113 & 54.9 & 50 & 64.1 & 0.283 \\
\hline No & 2 & 0.7 & 2 & 1.0 & 0 & 0.0 & \\
\hline $\begin{array}{l}\text { Undecided } \\
\text { Vaccination certificate shown? }\end{array}$ & 119 & 41.9 & 91 & 44.2 & 28 & 35.9 & \\
\hline $\begin{array}{l}\text { Vaccination certificate shown? } \\
\text { Yes }\end{array}$ & 115 & 40.5 & 80 & 38.8 & 35 & 44.9 & 0.516 \\
\hline No & 48 & 16.9 & 34 & 16.5 & 14 & 17.9 & \\
\hline No answer & 121 & 42.6 & 92 & 44.7 & 29 & 37.2 & \\
\hline \multicolumn{8}{|c|}{ Does your pet dog/cat go to other households or street for food? } \\
\hline Never & 139 & 48.9 & 92 & 44.7 & 47 & 60.3 & 0.057 \\
\hline Other" & 99 & 34.9 & 79 & 38.3 & 20 & 25.6 & \\
\hline Uncertain & 46 & 16.2 & 35 & 17.0 & 11 & 14.1 & \\
\hline
\end{tabular}

*Primary level: Includes no schooling, Kindergarten up to Grade 10 . †Secondary level and above: Has passed the General Certificate of Education, Ordinary Level Examination. \$The procedure is unnecessary, will cause infections, or make the pet sick. §No time to take pets to veterinarians, or unaware where to take pets. $\|$ Most of the time or sometimes.

drinking contaminated water) (pet owner: $-6.3 \%, P=$ 0.086 ; non-pet owner: $-8.8 \%, P=0.004)$; 2) adequate wound washing is the first thing to do after having been bitten by an animal (pet owner: $8.4 \%, P=0.002$; nonpet owner: $5.1 \%, P=0.093)$; 3) vaccination is a protective measure against rabies (pet owner: $4.9 \%, P=$ 0.508 ; non-pet owner: $9.4 \%, P=0.013$ ); and, 4) rabies vaccination should be repeated annually (pet owner: $12.4 \%, P=0.189$, non-pet owner: $18.3 \%, P=0.584$ ) (Table 4).

There was no improvement in knowledge when respondents were asked on the fatal nature of rabies (pet owner: $0 \%, P=0.508$; non-pet owner: $-2.7 \%, P=$ 0.625) (Table 4).

\section{Discussion}

We studied the level of KAP of study participants based on pet ownership status and educational level, and
Table 4. Change in KAP among respondents in selected areas of Nuwara Eliya, Sri Lanka.

\begin{tabular}{|c|c|c|c|c|c|c|}
\hline & \multicolumn{3}{|c|}{ Pet owner, $n=284$} & \multicolumn{3}{|c|}{ Non-pet owner, n=296 } \\
\hline & \multicolumn{2}{|c|}{ Intervention } & \multirow[b]{2}{*}{$p$ value } & \multicolumn{2}{|c|}{ Intervention } & \multirow[b]{2}{*}{$p$ value } \\
\hline & Pre & Post & & Pre & Post & \\
\hline \multicolumn{7}{|c|}{ Human rabies is almost always fatal } \\
\hline \multirow[t]{2}{*}{ True } & 257 & 257 & 0.508 & 262 & 254 & 0.625 \\
\hline & $90.5 \%$ & $90.5 \%$ & & $88.5 \%$ & $85.8 \%$ & \\
\hline \multicolumn{7}{|c|}{ Knows the most common mode of rabies transmission in Sri Lanka } \\
\hline \multirow{2}{*}{$\begin{array}{l}\text { Bite from an infected } \\
\text { animal }\end{array}$} & 244 & 258 & 0.045 & 234 & 257 & 0.015 \\
\hline & \multicolumn{5}{|c|}{ With misconceptions about rabies transmission ${ }^{*}$} & \\
\hline \multirow[t]{2}{*}{ No. of respondents } & 42 & 24 & 0.086 & 51 & 25 & 0.004 \\
\hline & $14.8 \%$ & $8.5 \%$ & & $17.2 \%$ & $8.4 \%$ & \\
\hline \multicolumn{7}{|c|}{ Which animal is the most common source of rabies in Sri Lanka? } \\
\hline \multirow[t]{2}{*}{ Dog } & 234 & 248 & 0.039 & 238 & 258 & 0.001 \\
\hline & $82.4 \%$ & $87.3 \%$ & & $80.4 \%$ & $87.2 \%$ & \\
\hline \multicolumn{7}{|c|}{ If bitten by an animal, what is the first thing that you would do to the bite wound? } \\
\hline \multirow[t]{2}{*}{ Wound wash } & 222 & 246 & 0.002 & 225 & 240 & 0.093 \\
\hline & $78.2 \%$ & $86.6 \%$ & & $76.0 \%$ & $81.1 \%$ & \\
\hline \multicolumn{7}{|c|}{ What would you do if the responsible animal develops symptoms of rabies? } \\
\hline \multirow{2}{*}{$\begin{array}{l}\text { Capture and send the } \\
\text { animal to laboratory }\end{array}$} & 30 & 223 & 0.000 & 26 & 210 & 0.000 \\
\hline & $10.6 \%$ & $78.5 \%$ & & $8.8 \%$ & $70.9 \%$ & \\
\hline \multicolumn{7}{|c|}{ In your community, is it required to register pet dogs? } \\
\hline \multirow[t]{2}{*}{ Yes } & 235 & 255 & 0.012 & 222 & 254 & 0.002 \\
\hline & $82.7 \%$ & $89.8 \%$ & & $75.0 \%$ & $85.8 \%$ & \\
\hline \multicolumn{7}{|c|}{ Do you think that you and your family are at risk for rabies? } \\
\hline \multirow[t]{2}{*}{ Yes } & 82 & 100 & 0.038 & 104 & 119 & 0.002 \\
\hline & $28.9 \%$ & $35.2 \%$ & & $35.1 \%$ & $40.2 \%$ & \\
\hline \multicolumn{7}{|c|}{ How can you protect dogs against rabies? } \\
\hline \multirow[t]{2}{*}{ Through vaccination } & 240 & 254 & 0.508 & 216 & 244 & 0.013 \\
\hline & $84.5 \%$ & $89.4 \%$ & & $73.0 \%$ & $82.4 \%$ & \\
\hline When is the earliest rabies & nation sc & lle for do & in Sri Lan & & & \\
\hline At 6 weeks old & 105 & 208 & 0.000 & 69 & 203 & 0.000 \\
\hline & $37.0 \%$ & $73.2 \%$ & & $23.3 \%$ & $68.6 \%$ & \\
\hline How often should a pet dog & accinatec & rabies? & & & & \\
\hline Every year & 208 & 243 & 0.189 & 175 & 229 & 0.584 \\
\hline & $73.2 \%$ & $85.6 \%$ & & $59.1 \%$ & $77.4 \%$ & \\
\hline Pet registration certificate & & & & & & \\
\hline Yes & 65 & 91 & 0.454 & & & \\
\hline & $22.9 \%$ & $32.0 \%$ & & & & \\
\hline Does your pet dog have a c: & & & & & & \\
\hline Yes & $\begin{array}{r}150 \\
52.8 \%\end{array}$ & $\begin{array}{r}169 \\
59.9 \%\end{array}$ & 0.003 & & & \\
\hline Do you allow your pet dog & am arour & isupervis & & & & \\
\hline Never & 115 & 84 & 0.006 & & & \\
\hline & $40.5 \%$ & $29.6 \%$ & & & & \\
\hline
\end{tabular}

evaluated the effects of rabies IEC materials concerning disease prevention, canine population control, and responsible dog ownership in three rural villages of $\mathrm{NE}$ District, Sri Lanka. As recommended in our previous work in Kandy District, this study focused on rural areas, which should be given the top priority in the implementation of rabies control programs since it constitutes the majority of the population, and may hardly be reached by awareness campaigns and modern diagnostic and treatment facilities. Because the security situation in Sri Lanka during the time of the survey did not allow for randomized selection of study areas, our priority population does not represent that of the country. In contrast to the Kandy survey (Sinhalese: 87.7\%; Buddhist: 86.5\%; primary educational level: $51.9 \%$ ) [10], the participants in this survey consisted mostly of Sinhalese, Buddhist, and individuals who had 
secondary levels of educational and above in rural areas. A similar exploratory study that focuses on urban areas, Tamils, and non-Buddhist populations (Hindus, Muslims, and Christians) would complement this investigation.

The results indicate that the there was greater preference for $\mathrm{ABC}$ rather than the dog elimination method, particularly among pet owners. Since only 10$16 \%$ of respondents affirmed that religion and personal beliefs influenced their choice of dog population control method, a more in-depth study is necessary to establish this intricate relationship. The Rabies Elimination Act of 2005 (REA) grants the responsibility to the local authorities (the Mayor of a Municipal Council area; the Chairman of an Urban Council area or Pradeshiya area; Medical Officer of Health; Veterinary Surgeon; Divisional Secretary; Secretary of Local Authority; and two members of the public) to approve the method of dog population control to be implemented within its area of jurisdiction and ensure that such activities are conducted in a hygienic and humane manner [36].

Public concern with the nuisance created by strays and unsupervised pets is shown by the participants' annoyance with and their enthusiasm to report these animals to proper authorities. Moreover, there are twice more pet owners than non-pet owners who believe that it is the responsibility of the people themselves and NGOs to control the population growth of these animals. Most pet owners in Sri Lanka keep their old or disabled dogs or give to other people their puppies instead of abandoning them (old/disabled pets: $1.0 \%$; puppies: $0.2 \%$ ).

These are good indicators of community involvement since most people, especially pet owners, feel accountable for the increase in the stray dog population and do not believe it is right to pass the responsibility solely to authorities. Under the REA, the local authority should take adequate measures to seize and detain all stray dogs for a period of not less than three days. If a dog is not claimed after that period, the proper authorities (Medical Officer of Health; Veterinary Surgeon of the local authority; Public Health Inspectors; every Police Officer; every village officer or Grama Niladari; and every authorized person) may cause the dog to be euthanized or otherwise disposed of in a humane manner [36]. It is important to note that elimination of stray dogs is recommended as a disease control measure, and not as a critical component in dog population management $[1,35]$.

The motivation of pet owners for canine inoculation did not correspond with their will to show documentary evidence. This could be due to the low vaccination coverage of the study areas to begin with, and/or the lack of awareness of the importance of record keeping. In a study by Perera et al., only $2.0 \%$ of the 627 vaccination cards that they examined had all the required information recorded in an acceptable manner [37].

This means that a major reason for people not to keep dog vaccination cards may be the poor recording of information on the cards, which reflects a lack of enthusiasm by the control program staff. Therefore, vaccinators should emphasize the importance of careful record keeping to pet owners.

The IEC materials were very effective mainly in informing the participants with how to deal with an animal suspected to be rabid, the earliest age for pets to receive anti-rabies vaccine (ARV), and repeat inoculation. They were also helpful in enhancing the awareness that adequate wound wash is the first line of action after animal bites, and that ARV provides protection against disease. Additionally, after reading the materials, more pet owners were able to show pet registration certificates, had built cages for their pets, and had fewer misconceptions with regard to rabies transmission than previously.

In Sri Lanka, dogs are the most important animals responsible for the transmission of the rabies virus [3839]. The REA requires that all dogs over six weeks of age be vaccinated [36]. However, recent reports have shown that the disease had been detected among puppies at the age of six weeks, the reason for initiating immunization at an earlier age [17,40,41].

There are varied reports with regard to the earliest vaccination schedule in the literature $[33,34,42,43]$. The WHO recommends rabies immunization for all dogs and cats regardless of age, weight or state of health $[30,44]$. Rabies vaccination drives are generally conducted annually but more frequent campaigns may be required in areas where dog population birth and death rates are high.

The WHO further recommends immediate and vigorous washing with soap and water after a dog bite. This procedure should be followed by application of $70 \%$ ethanol, or tincture or aqueous solution of iodine. Medical consultation should then be sought for administration of anti-rabies immunoglobulins. ARV should be given for contact with broken skin [45]. Under the REA, every dog shall be registered to the local authority by the age of three months. The owner or custodian will be liable to a fine of 5,000.00 rupees 
(approximately US\$46.36) if the dog does not possess a valid registration certificate [36].

In addition to the lack of improvement in knowledge about the fatality of human rabies, there were more pet owners who allowed their dogs to roam around unsupervised. The causes for the lack of improvement regarding knowledge of the fatal nature of the disease could be due either to the high preintervention awareness of more than $88 \%$, which may have passed the learning curve, or the need to emphasize more fully its importance in the IEC materials. Furthermore, there seems to be a disparity between building more cages and allowing for increased dog mobility among pet owners. This may be secondary to the latter's false sense of security and increased complacency after having known that if their dogs were vaccinated, registered, or if animal bite recipients followed the recommended first aid measures, then the risk of disease would be remote, which is incorrect. Therefore, supplementary educational materials such as audio-visual aids and workshops could reinforce their KAP.

A multi-centric KAP survey in India revealed that $60.7 \%$ of respondents had misconceptions with regard to rabies transmission; only $31.9 \%$ felt that wound washing is the best action immediately after dog bites; and bite wounds were treated by local application of chilies, turmeric powder, lime, kerosene, and herbal paste $(2.3 \%-11.4 \%)$ [46]. In another study in rural New Delhi, $84.0 \%$ of respondents were aware that dog bites might cause death, more than $50.0 \%$ preferred to kill the dog responsible for the bite, and as many as $48.0 \%$ of dog bite recipients used local home treatments such as chilies and salts [47].

In contrast to India, the participants of our survey showed higher pre-intervention levels of knowledge with regard to misconceptions on rabies transmission (16.0\%), adequate wound washing after dog bites (77.1\%), use of home or traditional remedies $(0.2 \%$, data not shown), and the fatal nature of rabies (89.5\%). Further, there were fewer participants who saw the dog elimination method as a solution to canine population problems (19.1\%-24.3\%). Sri Lanka's achievements in health status could be explained by a higher literacy rate and density of health workers, better public health infrastructure, and improved sanitation as a result of the pursuance of the social welfare-oriented state policy over the past decades [48-49]. However, a great deal of work has to be done in order to completely eliminate rabies.
In Asia, eight countries are free of rabies, namely, Bahrain, Hong Kong, Japan, Malaysia, Qatar, Singapore, Taiwan and the United Arab Emirates [50]. Japan and Malaysia have been rabies-free since 1957 and 1967, respectively [14,51-53]. It is thought that strict enforcement of dog registration and vaccination policies, and stray dog destruction have made rabies control and eradication effective in these countries $[14,19]$. To curb the disease in rabies-endemic Pakistan, the WISE approach was suggested. This focuses on wound washing (W), injection of immunogenic vaccines and immunoglobulins (I), and stray dog euthanasia (SE) [54]. In Sri Lanka, although legislation for registration and vaccination of animals are in place, they should be enacted uniformly and enforced effectively; otherwise, rabies elimination programs will only be a paper exercise.

It would be worthwhile to determine the retention and enhancement of rabies KAP in the medium- or long-term; therefore, subsequent follow-up surveys should be performed six or 12 months after the initial survey. This study could serve as a basis for more effective evidence-based rabies and dog population control programmes in the future. As an initial step, meetings are underway among stakeholders in the province to conduct rabies awareness and responsible pet ownership campaigns for school-age children who are at most risk for dog bites.

In conclusion, although there is an encouraging level of awareness and appropriate attitude toward rabies management and canine population control among the rural Sinhalese and Buddhist populations of Sri Lanka, their current health practices should be improved. The rabies KAP could be further enhanced through the use of IEC materials.

\section{Acknowledgements}

We thank the reviewers of this journal for their valuable and constructive comments. We express our gratitude to the following people for their cooperation and involvement in the realization of this survey: study participants; field interviewers and public health inspectors of Nuwara Eliya District; and translators and data encoders from the University of Peradeniya.

We appreciate Dr. Chaminda Weerakoon for his assistance in area selection; and Dr. Shanthi Samarasinghe for her permission to conduct the study in NE District. This study was partly financed by the 21st Century Center of Excellence Program of Hokkaido University, Japan.

\section{References}

1. World Health Organization (WHO) Regional Office for SouthEast Asia (2004) Prevention and control of rabies in the SouthEast Asia Region. 1-9. 
2. WHO Expert Consultation on rabies: first report. (2004) Geneva, World Health Organization.

3. Knobel DL, Cleaveland S, Coleman PG, Fèvre EM, Meltzer MI, Miranda MEG, et al. (2005) Re-evaluating the burden of rabies in Africa and Asia. Bull World Health Org. 83: 360-70.

4. Matter HC, Wandeler AI, Neuenschwander BE, Harischandra LPA, Meslin F-X (2000) Study of the dog population and the rabies control activities in the Mirigama area of Sri Lanka. Acta Tropica. 75: 95-108.

5. Department of Health Services Sri Lanka (2001) Annual Health Bulletin. 59-61.

6. The Rabnet Website of the WHO (2008) Available: http://www.who.int/globalatlas/default.asp. Accessed $2 \mathrm{Apr}$ 2008.

7. Public Health Veterinary Services, Ministry of Health, Sri Lanka (2003) National rabies control programme: Statistical bulletin.

8. Public Health Veterinary Services, Ministry of Health, Sri Lanka (2004) National rabies control programme: Statistical bulletin.

9. The Epidemiological Unit of the Ministry of Health of Sri Lanka (2007) Weekly Epidemiological Report.

10. Matibag GC, Kamigaki T, Kumarasiri PVR, Wijewardana TG, Kalupahana AW, Dissanayake DRA, De Silva DDN, Gunawardena GSP De S, Obayashi Y, Kanda K, Tamashiro H (2007) Knowledge, attitudes, and practices survey of rabies in a community in Sri Lanka. Environmental Health Prev Med. 12: 84-9.

11. Radhakrishnan S (1922) The Hindu Dharma. Internatl J Ethics. 33(1): 1-22.

12. Sunday Observer Website (2005) Improving standards of animal welfare. Available: http://www.sundayobserver.lk/2005/08/07/fea03.html. Accessed 27 Aug 2008.

13. Official Website of Sri Lanka (2006) Local government authorities directed to vaccinate dogs instead of killing. Available:

http://www.priu.gov.lk/news_update/Current_Affairs/ca200606 /20060613local_govt_authorities_directed_vaccinate_dogs.htm . Accessed 2 Apr 2008.

14. Tamashiro H, Matibag GC, Ditangco RA, Kanda K, Ohbayashi Y (2007) Revisiting rabies in Japan: is there cause for alarm? Travel Med Infect Dis. 5: 263-75.

15. Perera J (2006) Animal welfare Authority Bill handed over to Sri Lankan President. The Buddhist Channel. Available: http://singaporecommunitycats.wordpress.com/2006/06/27/ani mal-welfare-authority-bill-handed-over-to-sri-lankan-president/ Accessed 23 Mar 2007.

16. Edirisinghe D (2008) Rupees $100 \mathrm{mn}$ for President's 'no kill' policy. The Island Online. Available: http://www.island.lk/2008/04/03/news11.html. Accessed 14 Apr 2008.

17. Mitmoonpitak C, Tepsumethanon V, Wilde H (1998) Rabies in Thailand. Epidemiol Infect. 120: 165-169.

18. Palihawadana M (2006) The Buddha was against animal sacrifice. The Buddhist Channel. Available: http://www.buddhistchannel.tv/index.php?id=8,665,0,0,1,0 Accessed 27 Aug 2008.

19. Panichabhongse P (2001) The epidemiology of rabies in Thailand [dissertation]. NZ: Massey Univ.

20. Matibag GC, Ditangco RA, Kamigaki T, Wijewardana TG, Kumarasiri PVR, Kalupahana AW, Dissanayake DRA, De Silva DDN, Gunawardena GSP De S, Obayashi Y, Kanda K,
Tamashiro H (2008) Community-based evaluation of healthseeking behavior of people with animal bite injuries in a district of Sri Lanka. J Internatl Health. 23(3): 84-89.

21. Dhaliwal DS, Dhaliwal RS (2000) An analysis of 51 cases of hydrophobia at Amritsar (Punjab). Indian J Community Med. 25(3): 118-120.

22. Official Website of the Government of Sri Lanka (2 Jan 2008) Current affairs: Blast in Colombo. Available: URL: http://www.priu.gov.lk/news_update/Current_Affairs/ca200801 /20080102blast_in_colombo.htm Accessed 30 Aug 2008.

23. Official Website of the Government of Sri Lanka (16 Jan 2008) Current affairs: Explosion in Buttala. Available: URL: http://www.priu.gov.lk/news_update/Current_Affairs/ca200801 /20080116explosion_at_buttala.htm Accessed 30 Aug 2008.

24. Official Website of the Government of Sri Lanka (16 Jan 2008) Current affairs: Death toll rises to 26 in deadly terrorist attack. Available:

URL: http://www.priu.gov.lk/news_update/Current_Affairs/ca200801 /20080116death_toll_rises.htm Accessed 30 Aug 2008.

25. Official Website of the Government of Sri Lanka (31 Jan 2008) Current affairs: Suicide attack in Jaffna. Available at: URL: http://www.priu.gov.lk/news_update/Current_Affairs/ca200801 /20080131suicide_attack_in_jaffna.htm Accessed 30 Aug 2008.

26. Sri Lanka News First (2 Feb 2008) LTTE Terrorists target civilians in a bus bomb; 18 innocent civilians killed-Dambulla. Available at: URL: http://www.srilankanewsfirst.com/News/1377.html Accessed 2 Sept 2008.

27. Divisional Secretary of Nuwara Eliya of the Ministry of Health of Sri Lanka (2007).

28. Department of Census and Statistics of Sri Lanka Website (2005) Statistical abstract. Available: http://www.statistics.gov.lk/index.asp. Accessed 9 Jul 2006.

29. Department of Census and Statistics of Sri Lanka (2001) Census of population and housing, Nuwara Eliya District. [monograph on CD-ROM].

30. WHO (2005) Expert consultation on rabies. WHO Technical Report Series 931; 32.

31. Republic of the Philippines, Department of Health (Undated) Responsible pet ownership for rabies-free Philippines: a key leader's guide. Available: http://www2.doh.gov.ph/rabies_site/rabies_frameset.htm Accessed 27 Aug 2008.

32. Citrus County Animal Services (Undated) Some things to remember before you take me home. Available: http://www.citruscritters.com/ Accessed27 Aug 2008.

33. Pets V Care Website. FAQs (Undated): What is the vaccination schedule for dogs? Available: http://www.petsvcare.com/index.php?m=F.\%20A.\%20Q.\%20s \&he=F.\%20A.\%20Q.\%20s\&p=faq. Accessed 15 May 2008.

34. Investigative Guidelines Website (2004) Animal bites and rabies.

Available: http://www.oregon.gov/DHS/ph/acd/reporting/guideln/rabies.p df. Accessed 15 May 2008.

35. WHO/WSPA (1990) Guidelines for dog population management. Geneva: World Health Organization (WHO/Zoon/90.165).

36. Sri Lanka Rabies Elimination Act of 2005.

37. Perera ING, Pinidiyapathirage MJ, Wickremasinghe AR (2007) Rabies vaccination of domesticated dogs in the Central Province of Sri Lanka. Ceylon Med J. 52: 69-70. 
38. Goonaratna C (1997) Sri Lanka. Human rabies. In: Dodet, B, Meslin F-X, editors. Rabies control in Asia. 188-90.

39. Nanayakkara S, Smith JS, Rupprecht CE (2003) Rabies in Sri Lanka: splendid isolation. Emerg Infect Dis. 9(3): 368-371.

40. The Sunday Times on the web (1999) Even pups can get rabies. Available: http://www.sundaytimes.lk/991219/plus10.html. Accessed 15 May 2008.

41. The BBC News Website (2008) Social worker bitten by rabid dog. Available: http://news.bbc.co.uk/1/hi/uk/7368808.stm. Accessed 15 May 2008.

42. Foster R, Smith M, Nash H (No date) Vaccination recommendations for dogs. Available at: http://www.peteducation.com/article.cfm?cls=2\&cat=1648\&art icleid=950. Accessed 15 May 2008.

43. Dodds WJ (No date). Dr. Jean Dodds' recommended vaccination schedule. Available: http://www.weim.net/emberweims/Vaccine.html. Accessed 15 May 2008.

44. Dodet B, Meslin F-X, (Eds.) (2001) Fourth international symposium on oral rabies control in Asia. Symposium proceedings, 5-9 March 2001, Hanoi, Viet Nam. Montrouge, John Libbey Eurotext.

45. WHO (1996) WHO recommendations on rabies post-exposure treatment and the correct technique of intradermal immunization against rabies. WHO/EMC/ZOO/96.6.

46. Ichhpujani RL, Chhabra M, Mittal V, Bhattacharya D, Singh J, Lal S (2006) Knowledge, attitude and practices about animal bites and rabies in general community: a multi-centric study. Journal of Communicable Dis. 38(4): 355-362.

47. Agarwal N, Reddaiah VP (2003) Knowledge, attitude and practice following dog bite: a community-based epidemiological study. Health Population. 26(4); 154-161.

48. WHO (Undated) WHO Statistical Information System. Available: http://www.who.int/whosis/en/ Accessed 2 Sept 2008.

49. WHO (Undated) Country health profile: Sri Lanka. Available: http://www.searo.who.int/EN/Section313/Section1524_10875. htm Accessed 2 Sept 2008.

50. Beran GW, Steele JH (1994) Rabies and infections by rabies related virus. In: Beran GW. Handbook of Zoonoses, Section B, 2nd edition. CRC Press, Inc. Boca Raton, Ann Arbor. 307$357 \mathrm{pp}$.

51. Rahman A, Joseph PG (1985) Veterinary viral diseases: their significance in South East Asia and the Western Pacific. Academic Press: Sydney, Australia.

52. Shimada K (1971) The last rabies outbreak in Japan. Nagano Y and Davenport FM, editors. Rabies. Baltimore (MD): University Park Press.

53. Bisseru B (1972) Rabies. Weatherby Woolnough Ltd., Great Britain.

54. Aftab O, Jawaid A (2005) Rabies control in Pakistan: the WISE strategy. J Coll Physicians Surg-Pak. 15: 748.

Corresponding Author: Hiko Tamashiro, Department of Global Health and Epidemiology, Graduate School of Medicine, Hokkaido University, Sapporo, Japan

E-mail: tamashiro@med.hokudai.ac.jp

Conflict of interest: No conflict of interest is declared. 